\title{
Identifying trends in the development of marketing in the digital age
}

\author{
Natalia Alekseeva \\ Institute of Industrial Management, \\ Economics and Trade \\ Peter the Great St.Petersburg \\ Polytechnic University (SPbPU) \\ St. Petersburg, Russia \\ 0000-0002-7355-3277
}

\author{
Olga Stroganova \\ Institute of Humanities \\ Peter the Great St.Petersburg \\ Polytechnic University (SPbPU) \\ St. Petersburg, Russia \\ 0000-0001-5004-9193
}

\author{
Viktor Vasilenok \\ Saint Petersburg National Research \\ University of Information Technologies, \\ Mechanics and Optics (University \\ ITMO) \\ St. Petersburg, Russia
}

\begin{abstract}
Digital marketing has enormous potential to transform today's organizations and society as a whole fundamentally. The question of current interest is in what field the greatest changes will be achieved in the near future. An attempt to find the answer to the previously mentioned question is presented in the given work. The aim of the study is to identify trends in the development of marketing in the digital age based on the monitoring of scientometric databases. The universal bibliographic and abstract database Scopus was used for the analysis. As a result of data analysis, it was found out that such areas as digital marketing, online marketing, content marketing, email marketing, social media marketing are developing very quickly, their growth trends are exponential, the number of publications on web marketing, internet marketing and mobile marketing is insignificantly decreasing over the years. The work revealed a decreasing publication activity in the field of search engine marketing and search engine optimization. The trend of using big data in marketing is actively developing, thus, it is the field where the emergence of new business tools and new products using big data technology can be expected. The study shows that the United States is the leading country in the number of publications on all considered research topics in the field of marketing, while the second and third places almost always belong to the UK. Russia is in the top three for general research on the use of marketing in the digital economy.
\end{abstract}

Keywords-digital economy, digital marketing, online marketing, social media marketing, web marketing, internet marketing, mobile marketing

\section{INTRODUCTION}

Digital technologies have a significant impact on various areas of activity, including marketing. The sales of goods, works or services with the help of digital technologies are mainly conducted via the Internet, using mobile phones and other digital media. All the mentioned activities fall under the influence of digital marketing. The term "digital marketing" appeared in the 1990s. Digital marketing is the promotion of products or brands via one or more forms of electronic media [1]. The use of digital marketing in the era of digital technology not only allows companies to sell products, but also offers online customer service, which works 24 hours 7 days a week. It does not replace traditional marketing, but merely complements it, bringing new opportunities for firms to contact customers [2]. According to the analytical agency We Are Social and the SMM platform Hootsuite, more than 4 billion people use the Internet worldwide as of the end of 2018. The time that people spend online, using devices and services that depend on an Internet connection is about 6 hours a day as of 2018
[3]. Thus, the use of digital marketing can significantly expand the customer base [4]. The frames of time spent on the Internet are flexible. According to the agency We Are Social and Hootsuite's SMM platforms, in 2018 a little less than one million people daily started using social networks for the first time, which is more than 11 new users per second [5]. Changing users' time distribution on the Internet makes it necessary to use all new types and tools of digital marketing to attract customers [6]. A pressing issue of modern research is which of them will be most in demand in the future.

In the digital age, the market power of consumers is growing [7]. Social media and online reviews, allowing to give assessments and discuss products openly and publicly [8] as well as prices and customer service in different companies [9] can be considered an example of such a power. Many consumers take into account the experience of others while making decisions, thus even those products that meet their requirements, but have negative feedback from other consumers, will not be bought [10].

The use of social and media platforms, big data technologies in the process of digital marketing allows brands to obtain information about their customers [11], as well as determine which marketing tools work well for them [12]. Thus, it can be said that digital marketing provides an additional and significant advantage for brands [13] and enterprises [14].

Digital marketing is evolving and becoming more and more popular in the course of time [15]. It has already become or will become in the near future a part of almost all key business decisions, which range from product development [16] and pricing to public relations and even employee recruitment. Many companies have invested in digital solutions such as marketing automation [17], analytics, sales system [18], and social media [19]. As a result, digital marketing is in the process of constant change, so it is important to keep up with the times. The use of digital marketing is relevant not only in the field of trade $[8,9,15]$, but also in any sector of the economy, including production [14], construction [20], and the banking sector [16].

Digital marketing has enormous potential to transform today's organizations and society fundamentally. The question of current interest is where the greatest changes will be achieved in the near future. An attempt to find the answer to this important question is presented in the given work. The aim of the study is to identify trends in the development of 
marketing in the digital age based on the monitoring of scientometric databases.

\section{MATERIALS AND METHODS}

For the analysis of trends in the development of marketing in the digital age the universal bibliographic and abstract database Scopus was used. The search involved materials from scientific and professional journals, proceedings of conferences, serial books. Publications were not filtered by their types. The search was carried out in the names of publications, abstracts and keywords. In case the word "marketing" was contained in the term under study, the type of query was e. g., TITLE-ABS-KEY (digital W / 0 marketing). In the absence of the word "marketing", the type of query took the form e. g., TITLE-ABS-KEY (marketing AND media $\mathrm{W} / 0$ platforms).

The analysis was carried out as of June 20, 2019 and was performed over the period 2010-2018. The research indicator is the number of publications. The choice of key research terms is made on the basis of the work of T.V. Divina [21]

\section{RESULTS}

The article studied and analysed the publications on such types of marketing as digital marketing, online marketing, content marketing, email marketing, social media marketing, web marketing, internet marketing, mobile marketing (Table 1).

TABLE I. DYNAMICS OF PUBLICATION ACTIVITY ON VARIOUS TYPES OF MARKETING

\begin{tabular}{|c|c|c|c|c|c|c|c|c|}
\hline \multirow{2}{*}{ Year } & \multicolumn{8}{|c|}{ Marketing } \\
\hline & digital & online & content & email & social media & web & internet & mobile \\
\hline 2010 & 26 & 75 & 2 & 5 & 21 & 456 & 85 & 29 \\
\hline 2011 & 20 & 75 & 8 & 6 & 37 & 539 & 75 & 29 \\
\hline 2012 & 28 & 62 & 5 & 4 & 49 & 501 & 82 & 38 \\
\hline 2013 & 38 & 80 & 16 & 6 & 73 & 502 & 60 & 42 \\
\hline 2014 & 64 & 107 & 20 & 13 & 89 & 464 & 61 & 56 \\
\hline 2015 & 64 & 102 & 21 & 13 & 105 & 494 & 61 & 44 \\
\hline 2016 & 102 & 105 & 36 & 15 & 119 & 416 & 53 & 59 \\
\hline 2017 & 126 & 126 & 41 & 12 & 145 & 398 & 49 & 39 \\
\hline 2018 & 177 & 136 & 57 & 17 & 164 & 415 & 62 & 48 \\
\hline Total & 645 & 868 & 206 & 91 & 802 & 4185 & 588 & 384 \\
\hline Mean & 72 & 96 & 23 & 10 & 89 & 465 & 65 & 43 \\
\hline
\end{tabular}

The results of publication activity for 2018 presented in Table 1 are ranked in descending order and presented in Table 2.

TABLE II. RESEARCH RANKING ON VARIOUS MARKETING TYPES AS OF 2018

\begin{tabular}{|l|c|c|}
\hline \multicolumn{1}{|c|}{ Marketing } & $\begin{array}{c}\text { The number of } \\
\text { publications }\end{array}$ & $\begin{array}{c}\text { The share of } \\
\text { publications }\end{array}$ \\
\hline web & 415 & 0,39 \\
\hline digital & 177 & 0,16 \\
\hline social media & 164 & 0,15 \\
\hline online & 136 & 0,13 \\
\hline internet & 62 & 0,06 \\
\hline content & 57 & 0,05 \\
\hline mobile & 48 & 0,04 \\
\hline email & 17 & 0,02 \\
\hline Total & 136 & 57 \\
\hline
\end{tabular}

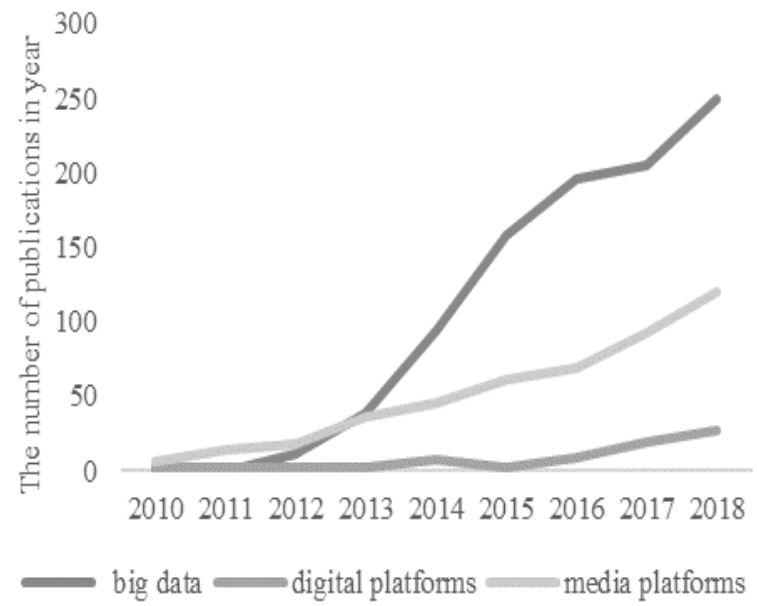

The increasing attention of marketing researchers is attracted by big data [22], digital platforms and media platforms [23], which is shown in Fig. 1.
Fig. 1. Increasing publication activity on topics within the scope of marketing 
Decreasing publication activity was identified in studies on search engine marketing (SEM), search engine optimization (SEO), website and blog.

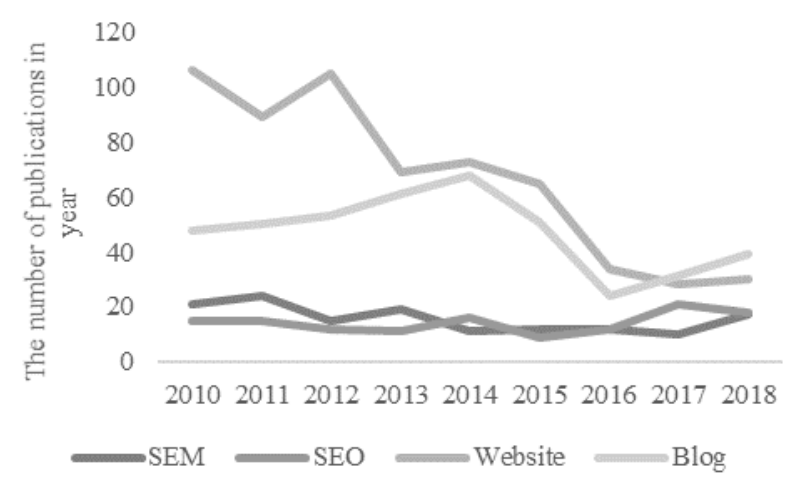

Fig. 2. Decreasing and stable publication activity on topics within the scope of marketing

\section{DISCUSSION}

According to the Scopus database, for the study period of 9 years, 96,327 papers devoted to marketing were published. On average, 10,703 papers (from 9,743 to 11,740 publications per year) are published annually. Therefore, it is possible to say that research in the sphere of marketing is the subject of scientific attention worldwide.

There are not so many generalized studies of marketing in the digital economy in the Scopus database: 23 publications in 2018, 8 in 2017, 6 in 2016, and 3 in 2015. One can see that such studies are increasingly attracting the attention of researchers. To a greater extent, this area is considered by researchers from the USA, Russia and Italy in descending order.

A larger number of publications are devoted not to general marketing issues in the digital economy, but to the types of marketing that could arise only in the digital age. As part of the work, publications on such types of marketing as digital marketing, online marketing, content marketing, email marketing, social media marketing, web marketing, internet marketing, mobile marketing were studied.

The results of the publication activity on these marketing types are presented in Table 1. Based on the result of the analysis of the data presented in Table 1, it was found out that digital marketing, online marketing, content marketing, email marketing, social media marketing are developing very quickly, their growth trends are exponential. The number of publications on web marketing, internet marketing and mobile marketing decreases slightly over the years. The ranking of publications according to various marketing types in the descending order of the number of publications in them presented in Table 2 shows that web marketing was the most popular among the authors. Despite the fact that a greater number of publications from all the types of marketing presented in Table 1 are devoted to the subject of web marketing, this trend ceases to attract the attention of researchers. This situation, we believe, is caused by the specification of web research field.

Digital marketing research occupies the second position in the ranking. The composition of types of digital marketing is currently the topic under discussion. The inclusion of social media marketing, online marketing, mobile marketing in the digital marketing is common, which leads to their being on the lower ranking lines. Email marketing is at the bottom of the ranking list. However, it should be mentioned that the number of studies in this area is gradually increasing, despite the fact that the use of email marketing is a rather old direction in terms of digital marketing.

The leading country in the research on types of marketing presented in Table 1 is the United States. This country occupies the first position in the number of publications on all types of digital marketing. In general, the second place is occupied by the United Kingdom, which sometimes occurs in the second place and sometimes in the third, depending on the type of digital marketing. The top three also includes China, India, Germany and Australia, while Russia is not even in the top 10 .

The increasing attention of marketing researchers is attracted by big data, digital platforms and media platforms. Data on the publication activity in these areas of research on marketing are presented in Fig. 1. The greatest interest is focused on the field of big data, despite the fact that these studies began only in 2012. Since then, the number of publications has been growing with an exponential dependence. Research on media and digital platforms is also developing rapidly in descending order. The greatest activity here is shown by scientists from the USA, Great Britain, China, India and Australia.

The initial hypothesis that in the field of marketing such areas as search engine marketing (SEM), search engine optimization (SEO), website and blog will be actively developing was not confirmed by the study (see Fig. 2). An average of 16 publications on SEM and 14 publications on SEO are published annually within the analysed period. It is significantly less than the number of studies, for example, in the field of online marketing. The amount of research into using website and blog in marketing is gradually decreasing. This confirms the previously identified trend in the field of web marketing, where the number of publications is also gradually falling. The leaders of publication activity on the search engine marketing (SEM), search engine optimization (SEO), website and blog are scientists from the United States, China and the United Kingdom.

\section{CONCLUSIONS}

The study shows a continuing interest in marketing in the digital age. Currently the scientific interest is focused on the following areas of marketing: digital marketing, online marketing, content marketing, email marketing, social media marketing. These directions have arisen only in connection with the general digitalization occurring worldwide. Such areas as digital marketing, online marketing, content marketing, email marketing, social media marketing are developing very quickly, their growth trends are exponential. Therefore, we can assume that the results of the application of research in these areas of marketing will have an impact on society in the near future.

Researchers are actively developing areas of big data in marketing. The leaders here are the USA, China and the UK. Therefore, it is here that one can wait for the emergence of new business tools and new products using big data technologies. 
For all considered research topics in the field of marketing, the United States is the leading country in the number of publications. In the second and third place is almost always the UK. Unfortunately, Russia is among the top three only in general research on the use of marketing in the digital economy.

\section{REFERENCES}

[1] A.I. Klimin, D.V. Tikhonov, A.I. Riushenkova, "Use of elements of native advertising in order to improve the effectiveness of media campaigns," Proceedings of the 32nd International Business Information Management Association Conference, IBIMA 2018 Vision 2020: Sustainable Economic Development and Application of Innovation Management from Regional expansion to Global Growth. Spain, vol. 1, pp. 8304-8310, November 2018 [32nd International Business Information Management Association Conference, IBIMA 2018].

[2] A.I. Klimin, D.V. Tikhonov, A.M. Efimov, "Evaluation of the effectiveness of marketing communications in Russian business using the example of St. Petersburg enterprises," Proceedings of the 30th International Business Information Management Association Conference, IBIMA 2017 - Vision 2020: Sustainable Economic development, Innovation Management, and Global Growth. Spain, vol. 1, pp. 1465-1482, November 2017.

[3] S.G. Bozhuk, A.S. Krasnov, "Methodics of research of consumers psychographic characteristics in the Internet," Proceedings of the 2017 International Conference "Quality Management, Transport and Information Security, Information Technologies, IT and QM and IS. Russian Federation, vol. 1, pp. 166-172, October 2017, DOI: 10.1109/ITMQIS.2017.8085790.

[4] P. Scheide, A.D. Marques, "How to communicate a new fashion brand through social media and public relations' perspective," IOP Conference Series: Materials Science and Engineering. Greece, vol. 459(1), no. 012097, September 2018. DOI: 10.1088/1757$899 X / 459 / 1 / 012097$.

[5] R. Sharmila, M. Kavitha, "Effectiveness of social media marketing," Indian Journal of Public Health Research and Development, 2018, vol. 9(11), pp. 192-196. DOI: 10.5958/0976-5506.2018.01450.X

[6] Ilin, I. V., Izotov, A. V., Shirokova, S. V., Rostova, O. V., \& Levina, A. I. (2017). Method of decision making support for it market analysis. Paper presented at the Proceedings of 2017 20th IEEE International Conference on Soft Computing and Measurements, SCM 2017, 812-814.

[7] Ilin, I.V., Iliashenko, O.Y., Klimin, A.I., Makov, K.M. Big data processing in Russian transport industry (2018) Proceedings of the 31st International Business Information Management Association Conference, IBIMA 2018: Innovation Management and Education Excellence through Vision 2020, pp. 1967-1971.

[8] I.A. Krasyuk, S.M. Krymov, Y.Y. Medvedeva, A.M. Chernisheva, S.I. Lashko, "Marketing management in retail chains," International Journal of Applied Business and Economic Research, 2017, vol. 15(12), pp. 83-91.

[9] E.B. Zolotukhina, V.V. Bakharev, I.V. Kapustina, S.V. Novikov, N.I. Lygina, "Sales management of the chain retail establishments," International Journal of Applied Business and Economic Research. International Journal of Applied Business and Economic Research, 2017, vol.15(11), pp. 19-27.

[10] D.S. Demidenko, A.A. Gorovoy, E.D. Malevskaia-Malevich, "The new elements of risk classification," (2017) Proceedings of the 29th International Business Information Management Association Conference - Education Excellence and Innovation Management through Vision 2020: From Regional Development Sustainability to Global Economic Growth. Austria, vol. 1, pp. 2217-2221, May 2017.
[11] K. Kantorová, P. Bachmann, "Social customer relationship management and organizational characteristics," Information (Switzerland), 2018, vol. 9(12), no. 306. DOI: 10.3390/info9120306.

[12] A.I. Klimin, D.V. Tikhonov, A.V. Trykov, "Methodological problems of NPS index application for measuring customer relationship in B2B," Proceedings of the 30th International Business Information Management Association Conference, IBIMA 2017 - Vision 2020: Sustainable Economic development, Innovation Management, and Global Growth. Spain, vol. 1, pp. 3149-3160, November 2017.

[13] T. Fejling, E. Torosyan, O. Tsukanova, O. Kalinina, "Special aspects of digital technology-based brand promotion," IOP Conf. Ser.: Mater. Sci. Eng. Russian Federation, vol. 497(1), no. 012027, April 2019, [2nd International Scientific Conference on Digital Transformation on Manufacturing, Infrastructure and Service, DTMIS 2018]. DOI:10.1088/1757-899X/497/1/012027.

[14] V.P. Semenov, A.S. Sokolitsyn, N.A. Sokolitsyna, "Marketing Activity Management Improvement for Small-Series Production Enterprises," Proceedings of the 2018 International Conference "Quality Management, Transport and Information Security, Information Technologies", IT and QM and IS 2018 Proceedings of the 2017 International Conference "Quality Management, Transport and Information Security, Information Technologies, IT and QM and IS". Russian Federation, vol. 1, pp. 382-384, October 2017, DOI: 10.1109/ITMQIS.2018.8525067.

[15] Borremans A.D., Zaychenko I.M., Iliashenko, O.Yu. Digital economy. IT strategy of the company development. MATEC Web of ConferencesVolume 170, 13 June 2018. International Science Conference on Business Technologies for Sustainable Urban Development, SPbWOSCE 2017. Paper number 010342017.

[16] D.A. Jacob, M. Rajeswari, "Enhancement of customers satisfaction through social media for brand building in banking sector," International Journal of Mechanical and Production Engineering Research and Development, 2018, vol. 8, pp. 1051-1056.

[17] O.V. Grishchenko, V.S. Kireev, L.I. Dubrova, M.B. Yanenko, R.Y. Vakulenko, "Organization, planning and control of marketing logistics," International Journal of Economics and Financial, 2016, vol. 6 (8Special), pp. 166-172.

[18] D.V. Shkurkin, I.A. Krasyuk, S.M. Krymov, I.G. Kazantseva, G.N. Zakharenko, "Sales policy and sales marketing system," International Journal of Applied Business and Economic Research, 2017, vol. 15(12), pp. 203-213

[19] M. Yadav, Z. Rahman, "The influence of social media marketing activities on customer loyalty: A study of e-commerce industry," Benchmarking, 2018, vol. 25(9), pp. 3882-3905. DOI: 10.1108/BIJ05-2017-0092.

[20] N. Alekseeva, N. Antoshkova, S.Pupentsova, "Application of the Monte-Carlo Simulation Method in Building and Energy Management Systems," Advances in Intelligent Systems and Computing. Russian Federation, vol. 983, pp. 257-266, December 2018. DOI: 10.1007/978-3-030-19868-8_26.

[21] T.V. Divina. "The main tools of digital marketing," Current questions of modern economy, 2019, no. 1, pp. 260-282. [in Rus.]

[22] A.I. Klimin, N.V. Pavlov, A.M. Efimov, Z.L. Simakova, "Forecasting the development of big data technologies in the Russian Federation on the basis of expert assessments," Proceedings of the 31st International Business Information Management Association Conference, IBIMA 2018: Innovation Management and Education Excellence through Vision 2020/ Italy, vol. 1, pp. 1669-1679, April 2018.

[23] J. An, H. Kwak, S.-G. Jung, J. Salminen, B.J. Jansen, "Customer segmentation using online platforms: isolating behavioral and demographic segments for persona creation via aggregated user data," Social Network Analysis and Mining, 2018, vol. 8(1), no. 54. DOI: 10.1007/s13278-018-0531-0. 